\title{
Diabetes Mellitus Prevalence and Burden among Community Acquired Pneumonia Patients
}

\author{
Reda Abdel Latif Ibrahem ${ }^{1}$, Mostafa El Najjar ${ }^{2}$, Mohamed Abdel Raouf Korani ${ }^{3}$ \\ ${ }^{1}$ Public Health and Community Medicine Department, Faculty of Medicine, Menoufia University, Egypt \\ 2,3 Internal Medicine Department, Faculty of Medicine, Menoufia University, Egypt
}

\begin{abstract}
Article Info
Article history:

Received Jan 10, 2018

Revised Mar 14, 2018

Accepted Mar 27, 2018

\section{Keyword:}

Community acquired

pneumonia

Diabetes mellitus

Prevalence

ABSTRACT

This work aimed at measuring the prevalence of Diabetes Mellitus among community acquired pneumonia (CAP) patients and declaring its effect on CAP patient's outcome. Both community acquired pneumonia and diabetes mellitus are common in Egypt, and patients with associated CAP and DM need special care and supervision. This prospective study was carried out on 108 CAP patients admitted to Abassia Chest Hospital during the period from January 2016 to December 2016. Clinical and radiological diagnosis of pneumonia and DM diagnosis were performed. DM recorded a prevalence of $39.8 \%$ among community acquired pneumonia patients. Disturbed level of consciousness is more frequent among diabetic patients than non diabetics. diabetic patients recorded higher rate of hospital admission, longer duration of hospital stay, higher rate of ICU admission and more sever pneumonia than among non diabetic patients. CURB-65 score showed significant positive correlation with $\mathrm{HbA} 1 \mathrm{c}$ of the patients. Associated communityacquired pneumonia and diabetes mellitus is frequent in our locality and labor a double burden on the affected patients leading to poorer prognosis, higher rate of hospitalization with longer duration of hospital stay and ICU admission. So CAP patients with DM need intimate care.
\end{abstract}

Copyright () 2018 Institute of Advanced Engineering and Science. All rights reserved.

\section{Corresponding Author:}

Reda Abdel Latif Ibrahem,

Department of Public Health and Community Medicine, Faculty of Medicine,

Menoufia University,

Shebin El-Kom city, Menoufia Governorate, Egypt, Tel: 002-048-2322411; 002-01095776864,

Fax: 002-048-2325116.

Email: reda_8083@yahoo.com

\section{INTRODUCTION}

Community acquired pneumonia (CAP) is the lower respiratory tract infection obtained outside the hospital or long term health care facility. It is diagnosed in the community or during the first 48 hours of a hospital admission [1]. CAP is one of the most common infections and a leading cause of morbidity and mortality worldwide. CAP caused by typical bacterial pathogens as Streptococcus pneumoniae, Haemophilus influenzae, and Moraxella catarrhalis. However, with the progress in technology and presence of novel diagnostic techniques, viral respiratory tract infections are being identified as common etiologies of CAP. Human rhinovirus and influenza virus are the most common viruses obtained from hospitalized patients admitted with CAP [2].

Diabetes mellitus (DM) is a group of metabolic disorders in which there is hyperglycemia over a prolonged duration. Uncontrolled diabetes associated with many sequalae and complications [3]. Diabetes mellitus (DM) is a significant public health problem, representing one of the most common chronic diseases worldwide and the upcoming emerging disease in $21^{\text {th }}$ century. It is associated with high morbidity and 
mortality. The increasing prevalence of DM and other comorbidities has been suggested as a triggering factor for the rising burden of infection-related hospitalizations [4]. Respiratory infections are among the major infections associated with diabetes [5]. Community-acquired pneumonia (CAP) is one of the most common infectious diseases requiring hospitalization in developed countries. On Association of DM with CAP, hospitalizations have been suggested previously. However, information regarding this combined burden and outcomes of CAP in patients with DM, specially its relationship with hospitalization and mortality expectation, is still limited [6].

Multiple scoring systems are available to assess the severity of CAP and to help in deciding whether a patient is in need for hospitalization or admission to the intensive care unit (ICU). The CURB-65 score is one of the scores recommended by the 2007 Infectious Diseases Society of America/American Thoracic Society Consensus Guidelines [7]. This work aimed at estimating the prevalence of Diabetes Mellitus among CAP patients admitted to Abassia chest hospital, Cairo, Egypt, and evaluation of its impact on CAP outcome. Glycated $\mathrm{Hb}(\mathrm{HbAlc})$ level represents the mean glucose concentration over the previous 8-12 weeks and provides better suggestion of long-term glycemic control than blood and urinary glucose [8].

\section{RESEARCH METHOD}

This prospective observational study was carried out in Abassia Chest Hospital within the period from January 2016 to December 2016 after taking a permission from committee of medical ethics and scientific research, faculty of Medicine, Menoufia University and taking a written consent from each patient. All patients diagnosed as CAP meeting inclusion and exclusion criteria of this study were enrolled. Patients aged $>18$ and $<80$ years, those presented with a new radiographic infiltrate. Showed at least two compatible clinical symptoms (eg, body temperature $>38^{\circ} \mathrm{c}$, productive cough, chest pain, shortness of breath, crackles on auscultation were included.

While he patients presented by conditions mimic pneumonia ,Heart failure, Liver cell failure, Renal failure, Cancer patients, Human immune-deficiency virus infection, Patients on hemodialysis, Chronic suppurative lung diseases, Been hospitalized in the last 90 days before the start of the study, TB patients, Hospital Acquired pneumonia, Ventilator associated pneumonia, COPD with acute exacerbation were excluded from this study. The total collected number in the study duration was 108 patients.

Informed consent was taken from each patient prior to their enrollment in the study. CAP patient was defined by the presence of an acute illness with two or more of the symptoms and signs of lower respiratory tract infection: fever, new or increasing cough or sputum production, dyspnoea, chest pain and new focal sign on chest examination and presence of infiltration in the chest radiograph on or within 48 hours of admission) that was consistent with acute infection [9]. CURB-65 scoring was done by calculating scores on confusion of new onset (Mini mental state score $\leq 8)$, respiratory rate $(\geq 30 / \mathrm{min})$, presence of hypotension (systolic blood pressure $<90 \mathrm{~mm}$ of $\mathrm{Hg}$ and diastolic blood pressure $\leq 60 \mathrm{~mm}$ of $\mathrm{Hg}$ ) on admission, blood urea nitrogen (BUN) level $(\geq 7 \mathrm{mmol} / \mathrm{L})$ and age ( $\geq 65$ years) [10].

A diagnosis of diabetes mellitus was based on history of treatment with oral anti-diabetic agents or insulin. Alternatively, diagnosis could be established during this episode of pneumonia when the fasting plasma glucose concentration was $\geq 126 \mathrm{mg} / \mathrm{dL}$ and/or 2 hours post load blood sugar was $\geq 200 \mathrm{mg} / \mathrm{dL}$ on two or more separate occasions or may be based on HbAlc level (>6.4) [11].

Immediate and short outcome was assessed; immediate outcome was defined as outcome of first setting in terms of hospital duration, improvement, referral to ICU, development of complications or mortality (outcome during the hospital course). Improvement of the patient means clinical wellbeing, improvement of blood chemistry (Renal function tests) \& radiological improvement.

\subsection{Statistical analysis}

The collected data was tabulated and analyzed using Statistical package for Social Science version 20 (SPSS Inc., Chicago, IL, USA). Quantitative data was described as mean, Standard deviation ( \pm SD) and range while numbers and percentage was the description of categorical data. Student $t$ test was used to compare two sets of normally distributed quantitative data meanwhile Mann Whitney $U$ test was used in comparing two groups of not normally distributed quantitative data. Chi squared test was used for comparing qualitative data and Spearman correlation was used to assess correlation between CURB-65 score and HbAlc. P value was considered significant at a value $\leq 0.05$.

\section{RESULTS AND DISCUSSION}

The current study was carried out on 108 CAP patients with mean age (51.20 \pm 17.79$)$ years and ranged from $18-80$ years, $65.7 \%$ of them were male with male to female ratio (1.9:1). The prevalence of diabetes mellitus among 
CAP patients were 43 cases (39.8\%). Diabetic CAP patients were of older age than non diabetic CAP patients; meanwhile there is no difference between them regarding sex distribution. CAP associated with DM cases showed significantly more frequent disturbed level of consciousness (51.5\% VS 10.7\%) than non diabetic CAP patients (P value $=0.001)$, while, there was no significant difference between diabetic and non diabetic CAP patients regarding systolic blood pressure, diastolic blood pressure, pulse and body temperature (Table 1).

Regarding Laboratory investigations, there was non significant difference between diabetic and non diabetic CAP patients regarding urea, $\mathrm{Sa} . \mathrm{O} 2 \%, \mathrm{Hb} \&$ platelets while TLC was significantly lower among diabetic group and HbA1c was of significantly higher level among diabetic CAP patients than those non diabetics ( $\mathrm{P}$ value $<0.001)$. Also, diabetic CAP patients were with more sever pneumonia as they show higher CURB 65 score than non diabetics (Table 1).

Table 1. Comparison between Diabetics \& Non Diabetics CAP Patients as Regards Age, Sex and

\begin{tabular}{|c|c|c|c|c|c|}
\hline & \multicolumn{5}{|c|}{ Clinical Data } \\
\hline & \multicolumn{3}{|c|}{ CAP patients } & \multirow{2}{*}{ Test of sig. } & \multirow{2}{*}{$P$ value } \\
\hline & Diabetic $(\mathrm{N}=43)$ & Non dia & $(\mathrm{N}=65)$ & & \\
\hline \multirow{2}{*}{$\begin{array}{l}\text { Age/years } \\
\mathrm{X} \pm \mathrm{SD}\end{array}$} & $58.08 \pm 16.08$ & \multicolumn{2}{|c|}{$47.76 \pm 17.71$} & $\mathrm{U}=2.89$ & 0.004 \\
\hline & No & No & $\%$ & $\mathrm{X}^{2}$ & \\
\hline \multicolumn{6}{|l|}{ Sex } \\
\hline Male & 62.8 & 44 & 67.7 & 0.28 & 0.60 \\
\hline Female & 37.1 & 21 & 32.3 & & \\
\hline \multicolumn{6}{|l|}{ Consciousness } \\
\hline Full & 45.5 & 61 & 93.8 & $\mathrm{X}^{2}=30.9$ & $<0.001$ \\
\hline Disturbed & 54.5 & 4 & 6.2 & & \\
\hline RBS & $286.47 \pm 112.54$ & \multicolumn{2}{|c|}{$123.25 \pm 32.49$} & $\mathrm{U}=7.59$ & $<0.001$ \\
\hline Respiratory rate & $33.67 \pm 8.92$ & \multicolumn{2}{|c|}{$30.71 \pm 9.35$} & t-test $=1.64$ & 0.10 \\
\hline Systole & $113.14 \pm 29.38$ & \multicolumn{2}{|c|}{$114.7 \pm 21.72$} & t-test $=0.32$ & 0.75 \\
\hline Diastole & $69.28 \pm 16.98$ & \multicolumn{2}{|c|}{$72.0 \pm 13.89$} & $\mathrm{t}$-test $=0.91$ & 0.36 \\
\hline Pulse & $108.48 \pm 13.65$ & \multicolumn{2}{|c|}{$103.21 \pm 13.87$} & t-test $=1.95$ & 0.05 \\
\hline Temperature & $39.06 \pm 1.17$ & \multicolumn{2}{|c|}{$38.97 \pm 0.72$} & $\mathrm{t}$-test $=0.50$ & 0.62 \\
\hline Urea & $58.38 \pm 36.01$ & \multicolumn{2}{|c|}{$46.85 \pm 28.25$} & $\mathrm{U}=1.58$ & 0.11 \\
\hline Sa. $\mathrm{O}_{2} \%$ & $88.60 \pm 7.53$ & \multicolumn{2}{|c|}{$91.78 \pm 8.76$} & $\mathrm{t}$-test $=1.95$ & 0.05 \\
\hline $\operatorname{TLC}\left(10^{3}\right)$ & $11.55 \pm 5.22$ & \multicolumn{2}{|c|}{$17.35 \pm 6.79$} & $\mathrm{U}=3.42$ & $<0.001$ \\
\hline $\mathrm{Hb}$ & $12.23 \pm 2.17$ & \multicolumn{2}{|c|}{$12.05 \pm 2.16$} & $\mathrm{t}$-test $=0.42$ & 0.67 \\
\hline Platelets $\left(10^{3}\right)$ & $236.67 \pm 85.37$ & 266. & 4.36 & $\mathrm{U}=1.37$ & 0.17 \\
\hline $\mathrm{Hb} \mathrm{A} 1 \mathrm{c}$ & $7.53 \pm 1.05$ & & & $\mathrm{t}$-test $=14.1$ & $<0.001$ \\
\hline CURB 65 score & & & & & \\
\hline 0 & $7(16.7)$ & & & & \\
\hline 1 & $4(8.3)$ & & & & \\
\hline 2 & $10(25.0)$ & & & $X^{2}=26.4$ & $<0.001$ \\
\hline 3 & $5(8.3)$ & & & & \\
\hline 4 & $10(25.0)$ & & & & \\
\hline 5 & $7(16.7)$ & & & & \\
\hline
\end{tabular}

CURB 65 score demonstrate significant positive correlation with HbA1c $(\mathrm{r}=+0.32, \mathrm{P}$ value $=0.001)$ (Figure 1). Regarding burden of combined CAP and DM, diabetic CAP patients showed prolonged hospital stay, higher rate of ICU admission and also higher rate of complicated cases with pleural effusion than non diabetics (54.5\% versus $24 \%$ ) respectively (Table 2$)$. 
Table 2. Comparison between Diabetics \& Non Diabetics Groups as Regards Hospital Stay, ICU Admission and Pleural Effusion

\begin{tabular}{|c|c|c|c|c|c|c|}
\hline & \multicolumn{4}{|c|}{ CAP patients } & \multirow{2}{*}{ Test of sig. } & \multirow{2}{*}{$\mathrm{P}$ value } \\
\hline & Diab & $=43)$ & Non I & $(\mathrm{N}=65)$ & & \\
\hline \multirow{2}{*}{$\begin{array}{l}\text { Hospital stay } \\
\mathrm{X} \pm \mathrm{SD}\end{array}$} & \multicolumn{2}{|c|}{$8.53 \pm 5.24$} & \multicolumn{2}{|c|}{$5.58 \pm 5.20$} & \multirow{2}{*}{$\begin{array}{c}\mathrm{U} \\
3.79\end{array}$} & \multirow{2}{*}{$<0.001$} \\
\hline & No & $\%$ & No & $\%$ & & \\
\hline ICU admission & & & & & \multirow{3}{*}{$\begin{array}{c}X^{2} \\
19.8\end{array}$} & \multirow{3}{*}{$<0.001$} \\
\hline Yes & 25 & 58.1 & 11 & 16.9 & & \\
\hline No & 18 & 41.9 & 54 & 83.1 & & \\
\hline Pleural effusion & & & & & \multirow{3}{*}{$\begin{array}{c}X^{2} \\
14.9\end{array}$} & \multirow{3}{*}{$<0.001$} \\
\hline Yes & 21 & 48.8 & 10 & 15.4 & & \\
\hline No & 22 & 51.2 & 55 & 84.6 & & \\
\hline Mortality & & & & & \multirow{3}{*}{$\begin{array}{c}\mathrm{FE} \\
0.52\end{array}$} & \multirow{3}{*}{0.60} \\
\hline Alive & 34 & 94.4 & 70 & 97.2 & & \\
\hline Dead & 2 & 5.6 & 2 & 2.8 & & \\
\hline
\end{tabular}

$\mathrm{X}^{2}=$ Chi square test, $\mathrm{FE}=$ Fisher's Exact test

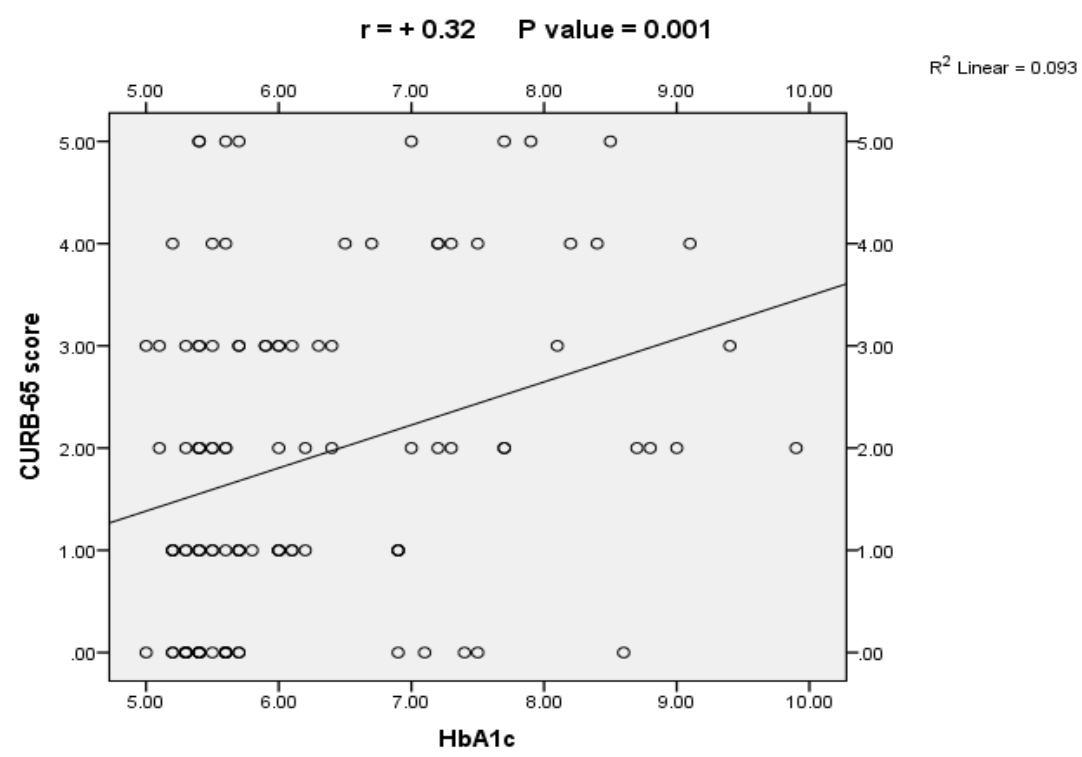

Figure 1. Spearman correlation between CURB -65 score and HbA1c among community acquired pneumonia patients

Based on the fact that DM produce hyperglycemic environment that induce immune dysfunction (e.g., damage to the neutrophil function, inhibition of the antioxidant system, and humoral immunity) consequently, DM increases the susceptibility to infections [10]. In our work, DM prevalence was $39.8 \%$ among community acquired pneumonia patients which is much more than a documented prevalence of diabetes mellitus type 2 in Egypt which was about $15.6 \%$ of adult populations with aged 20 to 79 [12] but it is in parallel with Khalil et al [13], whose study documented that $40.1 \%$ of CAP patients are with DM among Egyptian population sample, also, Akbar, 2001 [14] found that the prevalence of diabetes mellitus among CAP patients was 31\% in KSA, Martins et al, 2015[15] documents a higher prevalence of DM among CAP patients $(28 \%)$ which was larger than the prevalence in general population in Portugal ,furthermore, this significant association between DM and episodes of CAP was documented by de-Andrés et al, 2017 [16] and Kornum et al, 2007 [17].

According to our work, the associated DM and community acquired pneumonia was more frequent in older age patients, this due to the diminished immune system activity with age which predispose to infection, meanwhile, there is no association between this combination and sex of the patients, these results come in parallel with the results of_Saibal et al, 2012 [18], Falguera et al, 2005[19] and Akbar, 2001 [14]. The later observed male predominance in CAP diabetic patients. The current work shows a statistically higher rate of disturbed level of consciousness among diabetic patients than non diabetics $(51.5 \%$ Vs $10.7 \%)$ with insignificant difference between both groups regarding systolic \& diastolicblood pressure, temperature, pulse and respiratory rate. similar results were recorded by Saibal et al, 2012 [18] in the part that confirm altered 
mental status among diabetic CAP patients but it opposes our results as it found that hypotension and tachypnea are common clinical features in diabetic patients with CAP.

Regarding laboratory investigations, this study show significantly lower TLC among diabetic CAP patients which may be due to adverse effect of DM on immunity and resistance to infection. These results are in concordance with the studies of Akbar, 2001[14] \& Saibal et al, 2012 [18]. A higher rate of ICU admission and longer hospital stay among diabetic CAP patients was supported by Saibal et al, 2012 [18].

Our results revealed that diabetic CAP patients were presented with more sever pneumonia, longer hospital stay, higher rate of ICU admission and more frequent complication like pleural effusion, the same findings was observed by Saibal et al, 2012 [18] and Falguera et al, 2005[19]. According to the current study, HbA1c is positively correlated with CURB-65 score which determine the severity of pneumonia. This can be explained as HbA1c reflects diabetic control over the last 2-3 months and long term diabetic control is associated with protection from diabetic complications [20].

\section{CONCLUSION}

Associated community acquired pneumonia and diabetes mellitus is common, this association carries the double burden of both diseases reflected on more need for hospitalization and ICU admission, longer hospital stay and higher rate of mortality. So, special care for diabetic patients and intimate follow up for its control will lead to decline in exposure to infection and also less severe infection if any.

\section{REFERENCES}

[1] Chestnut M. S., et al., "Pulmonary disorder," in McPhee S. J. and Papadakis M. A., "Current Medical Diagnosis and Treatment," 48th ed, New York: Mc Graw Hill, pp. 23, 2009.

[2] Jain S., et al., "Community-Acquired Pneumonia Requiring Hospitalization among U.S. Adults," N Engl J Med, vol/issue: 373(5), pp. 415- 427, 2015.

[3] Kenny C., "When hypoglycemia is not obvious: diagnosing and treating under-recognized and undisclosed hypoglycemia," Primary care diabetes, vol/issue: 8(1), pp. 3-11, 2014.

[4] Korbel L. and Spencer J. D., "Diabetes mellitus and infection: an evaluation of hospital utilization and management costs in the United States," J Diabetes Complications, vol. 29, pp. 192-195, 2015.

[5] Smith S. A. and Poland G. A., "American Diabetes Association. Influenza and pneumococcal immunization in diabetes," Diabetes Care, vol/issue: 27(1), pp. S111-13, 2004.

[6] Torres A., et al., "Which individuals are at increased risk of pneumococcal disease and why? Impact of COPD, asthma, smoking, diabetes, and/or chronic heart disease on community-acquired pneumonia and invasive pneumococcal disease," Thorax, vol. 70, pp. 984-989, 2015

[7] Mandell L. A., et al., "Infectious Diseases Society of America/American Thoracic Society consensus guidelines on the management of community-acquired pneumonia in adults," Clin Infect Dis., vol/issue: 44(1), pp. S27-72, 2007.

[8] Liu J. L., et al., "Expanded CURB-65: a new score system predicts severity of community-acquired pneumonia with superior efficiency," Sci Rep, vol. 6, pp. 22911, 2016.

[9] Andrews J., et al., "Community-acquired pneumonia," Curr Opin Pulm Med, vol. 9, pp. 175-80, 2003.

[10] American Diabetes Association, "Diabetes Care," vol/iaaue: 38(1), pp. S8-S16. https://doi.org/10.2337/dc15-S005.

[11] Peleg A. Y., et al., "Common infections in diabetes: Pathogenesis, management and relationship to glycaemic control," Diabetes Metab Res Rev., vol. 23, pp. 3-13, 2007.

[12] Khalil M. M., et al., "Pattern of community and hospital acquired pneumonia in Egyptian military hospitals," Egyptian Journal of Chest Diseases and Tuberculosis, vol/issue: 62(1), pp. 9-16, 2013.

[13] International Diabetes Federation, “IDF Diabetes Atlas (7th ed.)," 2016. Available at http://www.diabetesatlas.org.

[14] Akbar D. H., "Bacterial pneumonia: comparison between diabetics and non diabetics," Acta Diabetol., vol/issue: 38(2), pp. 77-82, 2001.

[15] Martins M., et al., "Prevalence and impact of Diabetes mellitus (DM) among hospitalized community-acquired pneumonia (CAP) patients," European Respiratory Journal, vol. 46, pp. PA1104, 2015.

[16] de-Andrés A. L., et al., "Hospitalisation with community-acquired pneumonia among patients with type 2 diabetes: an observational population-based study in Spain from 2004 to 2013," BMJ, vol/issue: 7(1), pp. e013097, 2017.

[17] Kornum J. B., et al., "Type 2 Diabetes and pneumonia outcome," Diabetes Care, vol. 30, pp. 2251-2257, 2007.

[18] Saibal M. A., et al., "Community acquired pneumonia in diabetic and non-diabetic hospitalized patients: presentation, causative pathogens and outcome," Bangladesh Med Res Counc Bull., vol/issue: 3(3), pp. 98-103, 2012.

[19] Falguera M., et al., "Etiology and outcome of community-acquired pneumonia in patients with diabetes mellitus," Chest, vol. 128, pp. 3233-3239, 2009.

[20] Sato K. K., et al., "Combined measurement of fasting plasma glucose and A1C is effective for the prediction of type 2 diabetes: the Kansai Healthcare Study,” Diabetes Care, vol. 32, pp. 644-646, 2009. 